\title{
Por uma comunicação dissidente face ao assédio moral organizacional ${ }^{1}$
}

\author{
Cleusa Maria Andrade Scroferneker
}

Pontifícia Universidade Católica do Rio Grande do Sul, Porto Alegre, RS, Brasil ORCID: https://orcid.org/0000-0003-1450-2100

\section{Fernanda Luz Moraes}

Pontifícia Universidade Católica do Rio Grande do Sul, Porto Alegre, RS, Brasil ORCID: https://orcid.org/0000-0002-2721-950X

Luciana Buksztejn Gomes

Pontifícia Universidade Católica do Rio Grande do Sul, Porto Alegre, RS, Brasil ORCID: https://orcid.org/0000-0002-5513-989X

\section{Resumo}

Assédio moral e assédio moral organizacional são temas que, embora não sejam recentes, vêm merecendo alguns espaços de discussão. Em 2018, esse foi um dos temas que abordamos quando da realização do IV SICO-Seminário Internacional de Comunicação Organizacional ${ }^{2}$. Na oportunidade buscamos esclarecer a distinção entre essas duas modalidades de assédio, destacando as suas práticas mais contundentes e expressivas, mas também o seu lado nefasto, que têm no silenciamento, talvez, o seu lado mais perverso, ao tornar o outro um ser invisível. Consideramos os resultados da Pesquisa divulgada pelo Grupo de Planejamento de São Paulo e recorremos às decisões contidas em acórdãos ${ }^{3}$ - documentos públicos oriundos de decisões proferidas pelos Tribunais para refletir sobre a comunicação dissidente em ambientes organizacionais face ao assédio moral e assédio moral organizacional. Uma das nossas inquietações diz respeito à (im)possibilidade dos funcionários/empregados se manifestarem [e/ou tentarem se manifestar] para expressar uma posição contrária notadamente entendida pela gestão como enfrentamento.

\footnotetext{
1 Trabalho apresentado no Grupo de Trabalho (GT) Comunicação, ética e alteridades em processos relacionais de subjetivação e conflitos no ambiente organizacional, atividade integrante do XIV Congresso Brasileiro Científico de Comunicação Organizacional e de Relações Públicas.

2 Evento promovido pela Universidade Federal de Minas Gerais e Pontifícia Universidade Católica de Minas Gerais.

3 As decisões colegiadas proferidas pelos Tribunais são denominadas acórdãos. 0 julgamento é o ato de decidir o processo, e o acórdão é o documento escrito, composto pelo relatório e pelos votos de todos os Magistrados que tenham participado do julgamento, que é efetivamente juntado ao processo (TRIBUNAL REGIONAL DO TRABALHO DA 4르 REGIÃO, 2019).
} 


\section{Palavras-chave}

Comunicação organizacional; Assédio moral; Assédio moral organizacional

\section{Introdução}

Na contemporaneidade, a comunicação tem incorporado novas perspectivas, para além da linearidade transmissiva e consensual. Compreender que a realidade social é constituída por semelhanças e diferenças permite outros olhares sobre o processo de comunicação, considerando o valor do dissenso para as relações comunicacionais. Refletir sobre a comunicação dissidente em ambientes organizacionais face ao assédio moral e assédio moral organizacional, se constitui, portanto, no principal objetivo do artigo. Uma das nossas inquietações diz respeito à (im)possibilidade dos funcionários/empregados se manifestarem [e/ou tentarem se manifestar] para expressar uma posição contrária notadamente entendida pela gestão como enfrentamento.

Entre as diferentes modalidades/alternativas pelas quais os funcionários/empregados podem [tendem] a se manifestar no ambiente organizacional, encontra-se a dissidência4. Para Wainberg (2015, p. 116): "A Comunicação Dissidente se propõe a enfrentar e a desafiar certa ideia que é ou que aparenta ser hegemônica". Essa aparente hegemonia não emerge de situações isoladas, mas de construções baseadas em modelos e estruturas (re)construídas na confluência comunicação/cultura. Desta forma, a comunicação dissidente passa a ter como missão romper com o silêncio, considerando que as pessoas, muitas vezes, se protegem na unanimidade (WAINBERG, 2017).

É oportuno trazermos a analogia realizada por Ötken e Cenkci (2015), ao lembrarem-se do conto infantil A roupa nova do rei, de Hans Christian Andersen, publicado originalmente em 1837. O conto retrata a história de um rei apaixonado por roupas, e o vestir-se tomava todo seu tempo, até que um dia foi enganado por estrangeiros que se diziam tecelões e que criavam um tecido mágico. 0 rei encastelado em sua vaidade deixouse convencer pelos tecelões a vestir a roupa mágica e "bela" para o desfile na cidade. Porém,

\footnotetext{
4 Jetten e Hornsey (2013) estabelecem uma distinção terminológica entre o desvio (deviance) e a dissidência (dissent). Para elas, o desvio é a violação de normas de um grupo (sendo o seu "infrator" rotulado), ou porque não foram atendidas certas normas e/ou porque estas foram rejeitadas. Já a dissidência é a expressão da discordância sobre um grupo de normas, de ações e/ou decisões. Segundo as autoras, existem casos em que a dissidência pode ser considerada um desvio, motivo pelo qual é possível que os termos apareçam muitas vezes como sinônimos.
} 
a roupa era imaginária e o rei saiu nu. Seus súditos, vendo a situação, ficaram com medo de dizer ao rei que ele estava nu e acabaram agindo conforme as convenções estabelecidas: ninguém ousou contestar, e passaram a 'ver e admirar a roupa'.

O rei - nesse contexto - é a representação do sistema que constrói normas e convenções, pelo poder que exerce sobre os demais. Quando Ötken e Cenkci (2015) mencionam o conto, trazem a reflexão em torno de uma cultura similar com a realidade, com as relações humanas de poder, relações essas presentes nas organizações em seus diversos formatos. Para eles, "[...] evitar a expressar uma verdade indesejada ou opiniões contrárias ainda pode ser visto nas organizações de hoje" (ÖTKEN; CENKCI, 2015, p. 1): entrar em desacordo com o gestor nas organizações pode ser uma escolha arriscada (GARNER, 2016).

Nesse sentido, Bowman (2013) acredita que a conformidade se configura como uma norma organizacional implícita que acaba por dominar a estrutura de uma empresa. Alguns CEOs encorajam a conformidade e penalizam a dissidência; no entanto, líderes efetivos precisam fazer o contrário; em particular, devem "[...] encorajar a dissidência construtiva, ao invés do consentimento destrutivo" (TOURISH; VATCHA, 2005, p. 476). Desta forma, algumas lideranças defendem que a dissidência e suas múltiplas perspectivas são sinais de saúde organizacional (BAGHERI; ZAREI; AEEN, 2012).

Observamos que o sucesso é - muitas vezes - atribuído à conformidade de um funcionário às normas sociais e organizacionais dos comportamentos que são determinados pela gestão. Bowman (2013) defende, no entanto, a ideia do "desvio positivo"5, que tem um potencial de expandir a produtividade e de causar transformações, na medida em que torna as organizações mais adaptáveis, com características proativas e não reativas. No entanto, essa visão não parece ser a mais praticada nas organizações. 0 consenso ainda serve como um ideal a ser alcançado, sendo a dissidência algo que desestabiliza o sistema numa conotação negativa. Para Mafra e Marques (2014, p. 83):

0 consenso estabelece um enquadramento conceitual imagético para qualquer interação e discussão, cujas contradições passam desapercebidas por coincidirem com interesses hegemônicos ou por refletirem situações existentes e vistas como inalteráveis. (MAFRA; MARQUES, 2014, p. 83).

\footnotetext{
5 O desvio positivo pode ser definido como "[...] qualquer ação exibida [...] que viole ou evite a vontade declarada ou implícita da organização abrangente, motivada por propósito moral e sem qualquer intenção maliciosa [...]” (BOWMAN, 2013, p. 1).
} 
Talvez seja necessário um movimento no sentido de desconstruir a harmonia e o consenso como horizontes normativos ideais nas organizações (MAFRA; MARQUES, 2014), ou seja: "[...] tomar a dissidência como visada instauradora do diálogo nos contextos organizacionais [...]" (MAFRA; MARQUES, 2014, p. 84). É sob essa perspectiva que propomos a discussão sobre assédio moral e assédio moral organizacional, a partir da revisão teórica sobre o tema e suas interfaces, bem como recorrendo às decisões contidas em acórdãos ${ }^{6}$ documentos públicos oriundos de decisões proferidas pelos Tribunais (TRIBUNAL REGIONAL DO TRABALHO DA 4⿳亠丷厂 REGIÃO, 2019) - que exemplificam práticas que ferem a dignidade dos sujeitos que permeiam o ambiente organizacional e que se caracterizam como assédio moral organizacional. Nosso movimento de busca dos acórdãos iniciou-se por meio de consulta junto ao site do Tribunal Regional do Trabalho da $4^{a}$ região - órgão de $2^{\circ}$ grau da Justiça do Trabalho, que possui o Estado do Rio Grande do Sul como competência territorial (MORAES, 2021). Inicialmente, buscamos os acórdãos utilizando a expressão "assédio moral organizacional" como palavra-chave na busca, selecionando o período entre 1o de janeiro de 2015 e 31 de dezembro de 2018 (MORAES, 2021). Nessa busca relacionamos 215 acórdãos, os quais foram então lidos, para posterior análise, considerando as organizações presentes e reincidentes em relação ao assédio moral organizacional.

\section{Assédio moral e assédio moral organizacional}

Embora o assédio moral, em suas modalidades interpessoal e organizacional, não seja prática recente, tem ganhado notoriedade e visibilidade por conta das denúncias de empregados e, principalmente, pela aceitação, por parte da Justiça do Trabalho, dessas denúncias. Empresas nacionais e multinacionais são 'chamadas' a responderem por suas práticas pouco ortodoxas para engajar seus empregados. Livraria Cultura, Banco Santander, Carrefour, Walmart, dentre outras, são algumas dessas empresas.

Pesquisa divulgada pelo Grupo de Planejamento de São Paulo (2019) revelou essa prática nas Agências de Publicidade desse Estado. De acordo com o Grupo, o objetivo do estudo, em parceria com a Qualibest, foi o de "[...] mapear o problema do assédio sexual e

\footnotetext{
${ }^{6}$ As decisões colegiadas proferidas pelos Tribunais são denominadas acórdãos. 0 julgamento é o ato de decidir o processo, e o acórdão é o documento escrito, composto pelo relatório e pelos votos de todos os Magistrados que tenham participado do julgamento, que é efetivamente juntado ao processo (TRIBUNAL REGIONAL DO TRABALHO DA 4르 REGIÃO, 2019).
} 
moral no mercado para então contribuir com a melhora nos ambientes de trabalho das empresas do setor" (MEIO \& MENSAGEM, 2019).

A pesquisa "Hostilidade, silêncio e omissão: o retrato do assédio no mercado de comunicação de São Paulo" (MEIO \& MENSAGEM, 2019), realizada em forma de questionário online, sem identificação de nome ou de local de trabalho dos entrevistados (MEIO \& MENSAGEM, 2019), foi respondida por 1.400 pessoas, entre homens e mulheres, que trabalhavam em empresas de comunicação - em sua maioria agências de publicidade da região metropolitana de São Paulo. O dado mais emblemático, de acordo com os organizadores da pesquisa (MEIO \& MENSAGEM, 2019), é que a totalidade dos respondentes mencionou a existência de assédio nas empresas de comunicação, sendo que 90\% das mulheres referiram já ter sofrido alguma situação de assédio moral ou sexual, enquanto que o percentual entre os homens foi de 76\% (MEIO \& MENSAGEM, 2019).

A pesquisa igualmente revelou que: "Para $89 \%$ das mulheres e $85 \%$ dos homens, o assédio moral é algo que faz parte do cotidiano de trabalho". Dentre as práticas mais comuns dessa modalidade de assédio estão “[...] a cobrança de tarefas em prazos impossíveis de serem cumpridos, jornadas extenuantes de trabalho (incluindo noites, feriados e finais de semana) e humilhação moral por parte de superiores ou clientes" (MEIO \& MENSAGEM, 2019, não paginado).

Essas são algumas situações que materializam o que denominamos de relações perversas nos ambientes de trabalho, notadamente protagonizada por gestores e/ou que contam com sua anuência e que têm no silêncio, na omissão, na resignação, talvez o seu lado mais devastador. 0 assédio moral manifesta-se por/em condutas que expõem o trabalhador a situações humilhantes e constrangedoras, que são capazes de ocasionar ofensa à sua personalidade, dignidade e/ou à integridade psíquica e que tenham por consequência "[...] excluir a posição do empregado no emprego ou deteriorar o ambiente de trabalho, durante a jornada de trabalho e no exercício de suas funções" (NASCIMENTO; NASCIMENTO, 2014, p. 1267).

Farah (2016) complementa que o assédio moral pode ocorrer, ainda, fora da jornada de trabalho, dependendo das funções exercidas pelo assediado. No Brasil, as investigações realizadas acerca do tema assédio moral iniciaram no ano 2000, a partir dos estudos da médica Margarida Barreto, que conceitua a prática como: 
Uma conduta abusiva (gestos, palavras, comportamentos, atitudes) [...] que atente, por sua repetição ou sistematização, contra a dignidade ou integridade psíquica ou física de uma pessoa, pondo em perigo sua posição de trabalho ou deteriorando o ambiente de trabalho. (BARRETO, 2000, p. 245).

Para Inácio (2012, p. 25): “O assédio moral se caracteriza como uma ofensa, uma agressão que ocorre de maneira repetitiva e prolongada [...] transformando o local de trabalho num lugar hostil e de tortura psicológica". 0 assédio moral se dá por meio da intencionalidade e apoia-se no ato de desqualificar e fragilizar a vítima, com o objetivo de neutralizar seu poder (HELOANI, 2004).

Nesse sentido, a prática pode se manifestar por meio de duas modalidades: interpessoal - quando há um indivíduo como alvo específico, fazendo com que ele se torne prejudicado e/ou excluído - e organizacional, quando os sujeitos do assédio são coletivos e sua finalidade está presente na necessidade de aumento da produtividade dos indivíduos (FARAH, 2016). Enquanto que no assédio moral estamos diante de práticas de caráter individual, que podem ser identificadas de maneira isolada e/ou em pequenos grupos (SILVA, 2016), quando as condutas recaem sobre todos os funcionários de uma organização (SILVA; PIOLLI; HELOANI, 2017), em que os alvos são coletivos e indefinidos (FARAH, 2016) e que dizem respeito a "[...] situações na qual a violência estava inserida nas estratégias organizacionais" (SOBOLL, 2017, p. 16), estamos diante da prática de assédio moral organizacional7. Araújo (2006) atribui a identificação dessa forma de assédio como consequência dos novos métodos de organização da produção que,

[...] sucederam o abandono do modelo fordista e que compreendem um modelo mais fragmentado e individualizado de produção, propício à desarticulação da organização de classe dos trabalhadores e à introdução de modelos abusivos de gestão de mão-de-obra. (ARAÚJO, 2006, p. 6).

0 assédio moral organizacional, portanto, revela o sentido de uma rede perversa de relações (MENDES; ARAÚJO, 2012) que produz significados distintos e que se refletem na subjetividade do trabalhador. Ao admitirmos a subjetividade como a compreensão de mundo obtida a partir das experimentações vividas, percebemos que as vítimas dessa

\footnotetext{
0 assédio moral organizacional também pode ser definido na literatura como assédio organizacional, assédio institucional ou assédio moral coletivo (SILVA; PIOLLI; HELOANI, 2017).
} 
modalidade violenta vivenciam, por vezes, um ambiente de cultura de violência inserida na organização (MORAES; SCROFERNEKER, 2018). E essa cultura da violência, embora percebida e vivida, não é questionada e/ou mesmo enfrentada pelos atores organizacionais que dela fazem parte e a constituem. Concordamos com Freitas, Heloani e Barreto (2017, p. XV) quando afirmam que "o ambiente de trabalho tem se transformado numa arena insalubre e perigosa". Para os referidos autores (FREITAS; HELOANI; BARRETO, 2017, p. $\mathrm{XVI):}$

\begin{abstract}
A violência expressa no ambiente do trabalho contemporâneo pode ser uma manifestação segmentada de uma violência maior que encontra os seus fundamentos numa sociedade que vê na economia a resposta para todos os seus problemas e em um a organização do trabalho cada vez mais sem compromissos com o ser humano [...]. Trata-se, portanto, de uma violência assumida como efeito colateral simplesmente, ou seja, uma violência que se quer naturalizada.
\end{abstract}

Tais considerações nos levam a questionar sobre a comunicação dissidente, que amplifica o silêncio e a voz que se cala, que 'visibiliza' a cegueira assumida, a negação dos fatos e/ou situações que se revelam e se materializam cotidianamente nesses ambientes, impregnados de violência psíquica. Essa violência está "[...] ligada a exigências paradoxais impostas pela nova organização do trabalho" (FREITAS; HELOANI, BARRETO, 2017, p. 12), visto que essa nova organização "[...] faz parecer que os que têm emprego devem se submeter à degradação do clima de trabalho sem pestanejar, visto que são privilegiados; ter um emprego passa a ser um motivo para ser chantageado com a ameaça do desemprego (FREITAS; HELOANI, BARRETO, 2017, p. 35). Ao passo que “[...] o não-trabalhar, o estar desempregado, tende a ser um qualificador negativo, não raras vezes traduzidos em expressões acusatórias: vagabundo, sem vontade, malandro e marginal" (BALDISSERA, 2010, p. 65). Tal contexto pode levar o sujeito, a aceitar qualquer que seja a ocupação, ou manter-se nela, ainda que rodeada pela informalidade, precarização, condições desumanas e perversas. 


\section{As materialidades das práticas de assédio em organizações}

Ao recorrermos à jurisprudência do Tribunal Regional do Trabalho da $4^{\text {a }}$ região ${ }^{8}$, por meio de um recorte dos resultados da pesquisa de Mestrado de uma das autoras (MORAES, 2021), nos deparamos com decisões contidas em acórdãos ${ }^{9}$ - documentos públicos oriundos de decisões proferidas pelos Tribunais (TRIBUNAL REGIONAL DO TRABALHO DA 4⿳亠丷a REGIÃO, 2019) - que exemplificam práticas que ferem a dignidade dos sujeitos que permeiam o ambiente organizacional e que se caracterizam como assédio moral organizacional. Nosso movimento de busca dos acórdãos iniciou-se por meio de consulta junto ao site do Tribunal Regional do Trabalho da $4^{\underline{a}}$ região - órgão de $2^{\circ}$ grau da Justiça do Trabalho, que possui o Estado do Rio Grande do Sul como competência territorial.

O resultado encontrado (MORAES, 2021), ao utilizar a expressão "assédio moral organizacional" como palavra-chave na busca, selecionando o período entre $1^{\text {o }}$ de janeiro de 2015 e 31 de dezembro de 2018, foi de 215 acórdãos, sendo 44 acórdãos referentes ao ano de 2015, 47 documentos no ano de 2016, 75 relacionados a 2017 e 49 ao ano de 2018, como representado no gráfico (FIGURA 1).

Figura 1 - Acórdãos encontrados

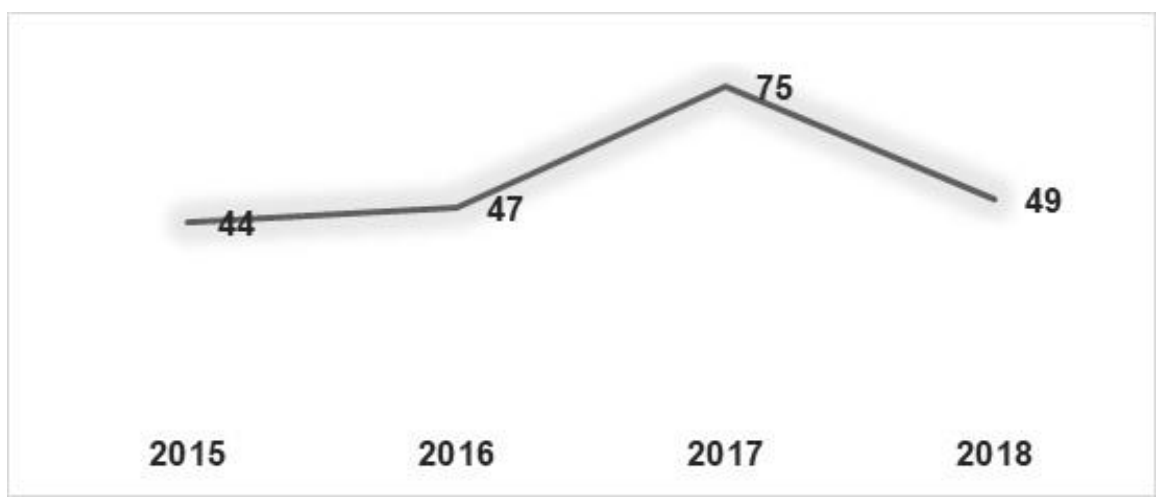

Fonte: Adaptado de Moraes (2021).

\footnotetext{
${ }^{8}$ Os Tribunais Regionais do Trabalho (TRTs) são órgãos de $2^{2}$ grau da Justiça do Trabalho no Brasil e julgam recursos interpostos contra decisões dos juízes das Varas do Trabalho, além de ações de sua competência originária, tais como dissídios coletivos de âmbito regional; ações rescisórias de decisões suas ou dos juízes das Varas; e mandados de segurança contra atos de juízes das Varas e desembargadores do TRT. Os TRTs ainda são competentes para o julgamento dos incidentes de uniformização de jurisprudência (IUJs), incidentes de resolução de demandas repetitivas (IRDR) e incidentes de assunção de competência (IAC) suscitados no âmbito de suas jurisdições (TRIBUNAL REGIONAL DO TRABALHO DA 4ª REGIÃO, 2019).

9 As decisões colegiadas proferidas pelos Tribunais são denominadas acórdãos. 0 julgamento é o ato de decidir o processo, e o acórdão é o documento escrito, composto pelo relatório e pelos votos de todos os Magistrados que tenham participado do julgamento, que é efetivamente juntado ao processo (TRIBUNAL REGIONAL DO TRABALHO DA 4르 REGIÃO, 2019).
} 
Em 123 documentos, foi considerada, por meio das provas e documentos contidos no processo jurídico, a existência da prática do assédio moral organizacional e em 12, apenas a assédio moral. Por outro lado, em 74 acórdãos não foi entendida como configurado ${ }^{10}$ assédio moral organizacional e 6 não foram revisados (MORAES, 2021).

Nesse movimento, elencamos as organizações que por mais vezes se repetiram como envolvidos nos acontecimentos que emergiram nos acórdãos (QUADRO 1):

Quadro 1 - Organizações

\begin{tabular}{ccc}
\hline ORGANIZAÇÃO & ACÓRDÃOS & $\begin{array}{c}\text { CONFIGURAÇÃO DE ASSÉDIO MORAL } \\
\text { ORGANIZACIONAL }\end{array}$ \\
Empresa Pública Federal & 49 & 22 \\
Instituições Bancárias & 32 & 16 \\
Supermercados & 24 & 21 \\
\hline
\end{tabular}

Fonte: Moraes (2021).

Entre as organizações envolvidas (QUADRO 1), nos chamou atenção uma prática considerada assédio moral organizacional, ocorrida na rede de supermercados Walmart, comprovada em 20 dos acórdãos referentes ao segmento supermercados (QUADRO 1). Trata-se do Cheers ${ }^{11}$ (BRASIL, 2018), uma dança motivacional realizada por funcionários do Walmart, em que há frases como “[...] Me dá um W!, Me dá um A!, Me dá um L!" (...) "WalMart é 10! Wal-Mart é 1.000! É o melhor varejista do mundo" (BRASIL, 2017). O cântico pode ocorrer no meio da loja, na presença de vários empregados e clientes ${ }^{12}$ ou em reuniões semanais (BRASIL, 2016) e consiste em, além de cantar, “[...] rebolar e movimentar os braços para cima e para baixo" (BOM DIA ADVOGADO, 2019).

Embora não seja obrigatória a participação dos funcionários na prática considerada "motivacional", os relatos contidos nos acórdãos analisados expõem que, embora eles não sejam forçados a participar,

10 Prática, existente, comprovada por meio de provas e documentos analisados no processo judicial pelo Desembargador do Trabalho.

11 A palavra cheers é originária da língua inglesa e sua tradução pode significar o ato de alegrar, dar vivas, torcer por alguém (DICIONÁRIO, 2000).

12 Há várias condenações do Walmart por parte dos tribunais Regionais do Trabalho no Brasil por essa prática abusiva que caracteriza assédio moral. 
[...] os chefes chamam, batendo nas costas, levando 2 funcionários de cada setor, no mínimo, para a reunião de piso; os escolhidos não podem recusar, pois, do contrário, é chamada a atenção, e ameaçam com melhoria; há um canto no meio do cheers, e deve se dar duas reboladas; se não fizer direito, deve-se repetir o rebolado. (BRASIL, 2015).

No referido acórdão (BRASIL, 2016) consta que, em decorrência da não participação, era possível a existência de punições, por meio da “[...] inclusão no denominado 'programa de melhoria', pelo qual o empregado ficava impedido de receber aumentos de salário, podendo inclusive ser despedido" (BRASIL, 2016). Tais acontecimentos expõem situações que, em seu bojo, revelam uma violência sutil e/ou velada, que fere a dignidade dos indivíduos que são obrigados a realizar atividades supostamente motivacionais. Em um primeiro momento, podem parecer alternativas divertidas para o cumprimento das tarefas e metas no ambiente de trabalho. Em realidade, invadem a intimidade dos sujeitos e causam constrangimento, na medida em que parte da jurisprudência entende que "a exigência de entonação de cânticos com realização de danças [...] extrapola o poder diretivo do empregador, ofendendo a dignidade e honra do indivíduo que é exposto a situação vexatória" (BRASIL, 2018).

A prática do cheers foi reconhecida como assédio moral organizacional em acórdãos, ao longo de todo o período analisado (FIGURA 1), e - por diversas vezes - a organização foi condenada ao pagamento de uma quantia financeira aos funcionários envolvidos. Mesmo assim, é possível perceber sua ocorrência desde período anterior ao analisado no presente artigo. Por outro lado, no ano de 2015 chegou a ser objeto de súmula13 proferida pelo Tribunal Regional do Trabalho da 4⿳亠丷厂 região, que considera que: "O empregado da empresa Walmart que é compelido a participar das reuniões motivacionais em que é entoado o cântico Cheers, com coreografia envolvendo dança ou rebolado, sofre abalo moral, tendo direito ao pagamento de indenização" (RIO GRANDE DO SUL, 2015). Entendemos que, muito embora as cobranças sejam acontecimentos naturais da atividade do trabalho, há circunstâncias excessivas em que os esforços físicos e mentais dos trabalhadores são postos à prova de superação. Tais situações ocorrem por/em um processo violento que extrapola, inclusive, os limites legais. 
Para Freitas, Heloani e Barreto (2017, p. 39): "Rituais degradantes e ofensivos podem ser desenvolvidos e justificados para punir os profissionais que não atingem as suas metas ou aqueles que têm a sua admissão ou permanência protegida legalmente (portadores de necessidades especiais, gestantes, ...)”. Ainda para os referidos autores:

\begin{abstract}
Em algumas organizações, esses rituais são considerados eventos "normais" da tradição gerencial que é defendida inocentemente por seus praticantes e seus superiores, como se fossem mero jogo consentido entre adultos vacinados e não como uma prática de assédio moral institucionalizada. (FREITAS; HELOANI; BARRETO, 2017, p. 40).
\end{abstract}

Talvez um dos grandes desafios, dentre tantos, que dizem respeito a essas práticas instituídas, naturalizadas e subestimadas pelas organizações, seja a busca por alternativas para minimizá-las e/ou mesmo evitá-las. A comunicação dissidente, sob nossa perspectiva, pode ser uma dessas alternativas, principalmente porque pressupõe contrariedade e divergência, sendo a “[...] expressão do desacordo ou opiniões contrárias sobre políticas e práticas no local de trabalho"14 (KASSING, 1998, p. 301, tradução nossa). A partir desta definição, surgem três aspectos importantes: a dissidência deve ser expressa para alguém, deve incluir opiniões contrárias e/ou determinado desentendimento, e deve se direcionar contra práticas, procedimentos ou operações da organização (CROUCHER; KASSING; LAWSON, 2013). Tais aspectos trazem consigo uma revelação contundente, ou seja, a necessidade de 'quebrar/romper' o silêncio. Para Wainberg (2017, p. 202),

[...] a missão da comunicação dissidente é a de romper o silêncio. Este registro retórico implica um ato comunicativo cujo significado é político. Ele revela o esforço que essa comunicação faz para vencer as barreiras existentes ao discurso. 0 falante faz emergir a voz que se mantinha calada e que hibernava até então sufocada à espera de melhores dias.

Fazer emergir as vozes, torná-las audíveis, sobre um tema como assédio moral e assédio moral organizacional é responsabilidade de todos em uma organização, mas sobretudo da gestão.

\footnotetext{
${ }^{14}$ No original: "Organizational dissent refers to the expression of disagreement or contradictory opinions about workplace policies and practices".
} 


\section{Considerações}

As relações perversas se manifestam, assim, no cotidiano do trabalho, marcadas pela (in)visibilidade das condutas que, ao longo do tempo e mediante pressupostos jurídicos, podem se configurar como práticas de assédio moral e assédio moral organizacional (MORAES, 2021). Tratam-se, portanto, de práticas que traduzem situações vexatórias que ferem, expõem e tentam silenciar algo - em nosso entendimento - tão valioso aos indivíduos, que é sua dignidade humana no ambiente de trabalho (MORAES, 2021).

A prática instituída do Cheers revela que um agir, conforme as regras seria o esperado, sendo penalizado aquele que não o fizesse. Ou seja, aquele que manifestasse entendimento contrário, se propondo a enfrentar e desafiar certa determinação, era punido. Em outras palavras, a comunicação dissidente acaba por não se manifestar, sendo no silêncio e na 'aceitação' (grifos nossos) da conduta que a hegemonia é estabelecida e o assédio moral organizacional se evidencia.

Embora a abordagem de Wainberg (2017) não envolva assédio, uma de suas afirmações traz uma contribuição significativa para esse tema, ou seja, "o valor terapêutico da verdade". Para esse autor: "[...] nos sistemas contaminados [como é o caso de muitas organizações], a tendência ao mimetismo social leva os sujeitos a copiarem comportamentos deletérios sob a justificativa de que a ilegalidade é a norma" (WAINBERG, 2017, p. 208), reiterando que: "Neste caso, romper ou quebrar o silêncio tem como objetivo salvar este sistema contaminado da morte" (WAINBERG, 2017, p. 208).

Nesse sentido, a contribuição daqueles que rompem com o silêncio e visibilizam as práticas de assédio moral organizacional, por meio da comunicação dissidente, são importantes também para que o sistema identifique e resguarde os direitos de todos, em especial, daqueles que fazem parte de certa realidade organizacional. Em cenários que, sob nossa perspectiva, são marcados - cada vez mais - pela precarização das relações de trabalho, em que a produtividade [não importando como] é vista como centralidade na organização, a comunicação dissidente pode ser uma possibilidade, também, para relações de trabalho mais saudáveis.

Esse é um tema que ainda carece de pesquisas, especialmente na área de comunicação organizacional e relações públicas. Talvez esteja aí uma possibilidade de ocuparmos um lugar como pesquisadores e/ou profissionais que assumem a comunicação dissidente, em e para além, das práticas, no cotidiano das organizações das quais fazemos 
parte. Recuperar, pelo diálogo, 'o valor terapêutico da verdade', pois como acreditam Mafra e Marques (2013, p. 93) "[...] o diálogo, enquanto instância de uma experiência humanizadora, deve ser capaz de revelar como sujeitos se constituem em interlocutores autônomos, valorizados por seus parceiros em cenas dissensuais”. São nessas cenas que “[...] estratégias, argumentos e formas de resistência se entrelaçam e evidenciam marcas de ruptura e potência na configuração de modos de tomar a palavra e não meramente de fazer escutar uma voz, ou um conjunto de vozes" (MAFRA; MARQUES, 2013, p. 93).

Esses movimentos/instâncias de dissenso, de resistência, de desvio ao se 'instalarem', ao provocarem fraturas/fissuras/rupturas, podem promover/e ou revelar a recuperação do protagonismo dos sujeitos, atores em cena, tomando a palavra.

\section{Referências}

ARAÚJO, Adriane Reis de. 0 assédio moral organizacional. 2006. Dissertação (Mestrado em Direito) - Programa de Estudos Pós-Graduados em Direito, Pontifícia Universidade Católica de São Paulo, São Paulo, 2006.

BAGHERI, Ghodratollah; ZAREI, Reihaneh; AEEN, Mojtaba Nik. Organizational Silence (Basic Concepts and Its Development Factors). Ideal Type of Management, Los Angeles, v. 1, n. 1, p. 47-58, 2012.

BALDISSERA, Rudimar. Organizações como complexus de diálogos, subjetividades e significação. In: A comunicação como fator de humanização das organizações. São Caetano do Sul: Difusão Editora, 2010.

BARRETO, Margarida. Uma jornada de humilhação. 2000. Dissertação (Mestrado em Psicologia) - Programa de Estudos Pós-Graduados em Serviço Social, Pontifícia Universidade Católica de São Paulo, São Paulo, 2000.

\section{BOM DIA ADVOGADO. Walmart deve pagar indenização a funcionário por dança motivacional, revista em bolsas e câmera em vestiário. [s.l.], 2019.}

BOWMAN, Brianna. Positive deviance in the workplace: expanding the boundaries of dissent. 2012. Dissertação (Mestrado em Comunicação) - Graduate Faculty, Baylor University, Texas, 2013.

BRASIL. Tribunal Regional do Trabalho (4. Região, 2. Turma). Recurso Ordinário no 0021682-45.2017.5.04.0271. Dano moral. Ato motivacional "Cheers". Recorrente: Isair da Silva Dias. Recorrido: WMS Supermercados do Brasil Ltda. Relatora: Desembargadora Brígida Joaquina Charão Barcelos Toschi, 19 de setembro de 2018.

CROUCHER, Stephen M.; KASSING, Jeffrey W.; DIERS-LAWSON, Audra R. Accuracy, coherence, and discrepancy in self- and other-reports: moving toward an interactive 
perspective of organizational dissent. Management Communication Quarterly, Los Angeles, v. 27, n. 3, p. 425-442, 2013.

DICIONÁRIO Oxford Escolar: para estudantes brasileiros de inglês. Oxford: Oxford University Press, 2000.

FARAH, Bruno. Da depressão ao assédio moral organizacional: efeitos humanos do poder paradoxal nas empresas pós-disciplinares. In: FARRAH, Bruno Leal (org). Assédio moral e organizacional: novas modulações do sofrimento psíquico nas empresas contemporâneas. São Paulo: LTr, 2016.

FREITAS, Maria Ester de; HELOANI, José Roberto; BARRETO, Margarida. Assédio moral no trabalho. 5. ed. São Paulo: Cengage Learning, 2017.

GARNER, Johny Thomas. Open doors and iron cages: supervisors' responses to employee dissent. International Journal of Business Communication, Los Angeles, v. 53, n. 1, p. 27 54, 2016.

GRUPO DE PLANEJAMENTO DE SÃO PAULO. Hostilidade, silêncio e omissão. 2019. Disponível em: https://grupodeplanejamento.com/hostilidade-silencio-e-omissao. Acesso em: 10 fev. 2020.

HELOANI, Roberto. Assédio moral: um ensaio sobre a expropriação da dignidade no trabalho. Revista RAE-eletrônica, São Paulo, v. 3, n. 1, art. 10, jan./jun. 2004.

INÁCIO, Aparecido. Assédio moral no mundo do trabalho: doutrinas, comentários, jurisprudência e casos concretos. São Paulo: Ideia \& Letras, 2012.

JETTEN, Jolanda; HORNSEY, Matthew J. Deviance and dissent in groups. Annual Review of Psychology, Palo Alto, v. 65, p. 461-485, 2013.

KASSING, Jeffrey W. Articulating, antagonizing, and displacing: a model of employee dissent. Communication Studies, London, v. 48, n. 7, p. 311-332, 1998.

MAFRA, Rennan Lanna Martins; MARQUES, Angela Cristina Salgueiro. Diálogo, cenas de dissidência e públicos como evento em organizações. Revista Latinoamericana de Ciencias de la Comunicación, [s.l.], v. 11, n. 21, 2014.

MAFRA, Rennan Lanna Martins; MARQUES, Angela Cristina Salgueiro. Diálogo no contexto organizacional e lugares de estratrégia, argumentação e resistência. Revista Organicom, São Paulo, v. 10, n. 19, 2013.

MEIO \& MENSAGEM. Assédio nas agências: 90\% das mulheres já foram vítimas. 2017. Disponível em:

https://www.meioemensagem.com.br/home/comunicacao/2017/11/15/assedio-nasagencias-90-das-mulheres-ja-foram-vitimas.html. Acesso em: 10 fev. 2020.

MENDES, Ana Magnólia; ARAÚJO, Luciane Kozicz Reis. Clínica psicodinâmica do trabalho: o sujeito em ação. Curitiba: Juruá, 2012. 
MORAES, Fernanda Luz. Comunicação e assédio moral organizacional: paisagens (in)visíveis do mundo do trabalho. 2021. Dissertação (Mestrado em Comunicação Social) Programa de Pós-Graduação em Comunicação Social, Pontifícia Universidade Católica do Rio Grande do Sul, Porto Alegre, 2021.

MORAES, Fernanda Luz; SCROFERNEKER, Cleusa Maria Andrade. Assédio moral organizacional: o papel da comunicação face às relações perversas no mundo do trabalho. In: CONGRESSO BRASILEIRO DE CIÊNCIAS DA COMUNICAÇÃO, 41., 2018, Joinville. Anais [...]. São Paulo: Intercom, 2018.

NASCIMENTO, Amauri Mascaro; NASCIMENTO, Sônia Mascaro. Curso de direito do trabalho: relações individuais e coletivas do trabalho. 29. ed. São Paulo: Saraiva, 2014.

ÖTKEN, Ayse Begüm; CENKCI, Tuana. Big five personality traits and organizational dissent: the moderating role of organizational climate. Business and Economics Research Journal, Bursa, v. 6, n. 2, p. 1-23, 2015.

RIO GRANDE DO SUL. Tribunal Regional do Trabalho (4.). Súmula ${ }^{\circ} 83.0$ empregado da empresa Walmart que é compelido a participar das reuniões motivacionais em que é entoado o cântico Cheers, com coreografia envolvendo dança ou rebolado, sofre abalo moral, tendo direito ao pagamento de indenização. Resolução Administrativa no 47/2015. Diário Eletrônico da Justiça do Trabalho: 20, 23 e 24 de novembro de 2015. Disponível em: https://www.trt4.jus.br/portais/trt4/sumulas. Acesso em: 27 fev. 2020.

SILVA, Eduardo Pinto; PIOLLI, Evaldo; HELOANI, José Roberto. Direitos Humanos sob ameaça: organizações patogênicas, trabalho e subjetividade. Educação: Teoria e Prática. São Paulo, v. 27, n. 54, p. 113-132, jan./abr. 2017.

SILVA, Jorge Luiz de Oliveira da. A síndrome de burnout como consequência do assédio moral no ambiente de trabalho. In: FARAH, Bruno Leal (org). Assédio moral e

organizacional: novas modulações do sofrimento psíquico nas empresas contemporâneas. São Paulo: LTr, 2016.

SOBOLL, Lis Andréa. Assédio moral e organizacional na perspectiva psicossocial: critérios obrigatórios e complementares. In: SOBOLL, Lis Andrea Pereira (org). Intervenções em assédio moral e organizacional. São Paulo: LTr, 2017.

TOURISH, Dennis; VATCHA, Naheed. Charismatic leadership and corporate cultism at enron: the elimination of dissent, the promotion of conformity and organizational collapse. Leadership, Los Angeles, v.1, n. 4, p. 455-480, 2005.

TRIBUNAL REGIONAL DO TRABALHO DA 4⿳a REGIÃO. Estrutura no Brasil e no RS. 2019. Disponível em: https://www.trt4.jus.br/portais/trt4/estrutura. Acesso em: 27 fev. 2020.

WAINBERG, Jacques Alkalai. A regra dos pares, o jornalismo e a comunicação dissidente. Estudos em Jornalismo e Mídia, Florianópolis, v. 12, n. 1, p. 110-120, jan./jun. 2015. 
WAINBERG, Jacques Alkalai. A comunicação dissidente e os atos que falam. Revista FAMECOS: mídia, cultura e tecnologia, Porto Alegre, v. 24, n. 1, 2017.

\title{
For dissenting communication in face of organizational bullying
}

\begin{abstract}
Moral harassment and organizational moral harassment are topics that, although not recent, have been deserving some space for discussion. In 2018, this was one of the themes we addressed when the IV SICO-International Seminar on Organizational Communication was held. On this occasion, we seek to clarify the distinction between these two forms of harassment, highlighting their most forceful and expressive practices, but also their nefarious side, which has perhaps its most perverse side in silencing, making the other an invisible being. We consider the results of the survey released by the Planning Group of São Paulo and resort to decisions contained in judgments - public documents arising from decisions rendered by the Courts to reflect on dissident communication in organizational environments in the face of moral harassment and organizational moral harassment. One of our concerns is the (im)possibility of employees/employees to express themselves [and/or try to express themselves] to express a contrary position - notably understood by management as a confrontation.
\end{abstract}

\section{Keywords}

Organizational communication; Moral harassment; organizational bullying

\section{Autoria para correspondência}

Luciana Buksztejn Gomes

lucianabg.adv@gmail.com

\section{Como citar}

SCROFERNEKER, Cleusa Maria Andrade; MORAES, Fernanda Luz; GOMES, Luciana Buksztejn. Por uma comunicação dissidente face ao assédio moral organizacional. Intexto, Porto Alegre, UFRGS, n. 52, e102850, jan./dez. 2021. DOI: http://dx.doi.org/10.19132/1807-8583202152.102850

Recebido em 10/05/2020

Aceito em 02/08/2021 